\title{
THE EFFECT OF TEMPERATURE ON ELONGATION TO FAILURE IN NANOSTRUCTURED MATERIAL FABRICATED BY ARB PROCESS
}

\section{PETER BAONHE SOB}

Department of Mechanical Engineering, Faculty of Engineering and Technology, Vaal University of Technology,

Vanderbijlpark 1900, Private BagX021, South Africa

\begin{abstract}
A nanostructured material was produced by accumulated roll bonding (ARB) process after several passes. The grain dislocation, grain rotation, grain curvature angles and the fraction of high angle grain boundaries increased as the $A R B$ cycles increases. During $A R B$ cycles, the material was observed to elongate more as the temperature in the material increases due to adiabatic warming that takes place during ARB cycles. The optimum temperature on the material was achieved for maximum elongation to failure. This causes more material elongation at higher temperature and material fatigue takes at the maximum temperature during ARB cycles. The obtained results revealed indication of material fracture surfaces in higher temperature after several ARB cycles than in lower temperature. The reason for this was due to deeper, bigger, and longer being observed in high temperature elongation than in low temperature elongation range during $A R B$ cycles.
\end{abstract}

KEYWORDS: Elongations, Temperature, ARB Cycles, Nanostructured \& Ultra-Fine Grain

Received: Jan 25, 2021; Accepted: Feb 15, 2021; Published: Mar 24, 2021; Paper Id.: IJMPERDAPR202129

\section{INTRODUCTION}

Materials are called Polycrystalline when their grain sizes are less than $1.0 \mu \mathrm{m}$ and these materials also are defined as ultrafine grained (UFG) materials [1-33]. For over the years now, several researchers have showed that most UFG materials have the potentiality or capability of exhibiting a vast range of higher mechanical properties, specifically these materials have improved facture roughness in nanostructured material with exceptional magnetic properties of the material [1-44]. Most nanostructured materials areproduced through different techniques and most of these techniques involve the application of severe plastic deformation (SPD) [1-33]. There are different techniques of SPD processes and most of these techniques include Accumulative roll bonding (ARB), equalchannel angular pressing (ECAP), cyclic extrusion and compression (CEC), and high-pressure torsion (HPT). Among all these techniques, the ARB process is more useful due to it significant advantages such as better mass production potentials as the ARB process are easily used in realizing bulk nanostructured metals [2, 3\& 29].

During SPD process, specifically during ECAP and ARB when a load is applied to my material during deformation process, the materials grain gets elongated along more on the principal deformation direction and along other plane of deformation. More so, when applying SPD processes to deform a material, elongated grain in the main direction of deformation in the microstructure achieved [4-6]. During deformation process, the deformed material through SPD exhibits more enhanced strength than coarse grained metals [1-44]. The deformed material has high density of grain boundaries and the material is thermally unstable [1-33]. Among all the SPD, the ARB is more continuous during manufacturing and therefore the ARB does not have greater production challenges like 
other SPD methods [14]. This process experiences high grain elongation and the material easily suffers from fatigue due to high elasticity and plasticity during elongation and if the material temperature is not well controlled this leads to elongation to failure being observed as material failure during ARB process [14]. In this study, the working conditions of ARB process and the deformation cycles on temperature are important parameters being investigated. These factors usually change during ARB process and impact the properties of the material thermal stability in the microstructure due to adiabatic warming. Due to the change in adiabatic warming during ARB process, the matrix and material grain boundaries mobility are impacted and therefore, the effect of temperature during ARB process impacts the properties of a material. Most nanomaterial after AR showed elongated UFG structured and they are thermally unstable at high temperature [1455]. The aim of this paper is to investigate the effect of temperature on elongation after several ARB cycles in order to find the optimal temperature to achieve maximum elongation

\section{MATERIALS AND METHODS}

The materials were deformed by the ARB setup as shown in Figure 1 through the rolling mill facility. During experimentation process, the material being deformed was forced or fed through the rotating shafts in the first pass. The rolling shafts gripped the sample and forced the sample through the rollers. The deformed materials were cut into two pieces and stacked together and roll for another pass. Before stacking the material, the entire material surfaces of the strips were clean by a wire-brushed and degreased with tetrachloroethylene to achieve the desire bonding. The deformed materials were joined by using aluminum wires and the joined material was subsequently rolled for another pass. The process of "rolling, cutting, face-brushing, degreasing and stacking" was repeated for several "passes or cycles" until nanomaterials with required characteristics were produced. The initial samples and the deformed samples were examined using Transmission Electron Microscopy (TEM) to get the variables of grain elongation and the elongation of principal deformation direction along the elongation lengths along the major axis $r 3$, semi major axis $r 1$ and semi minor axis $r 2$ as shown in figure $1(\mathrm{a}-\mathrm{b})$

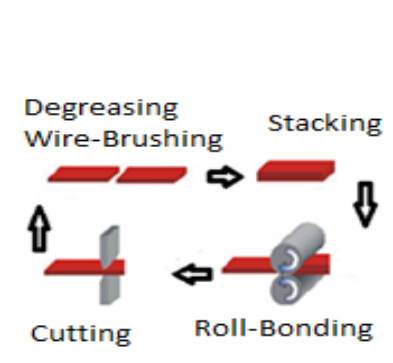

(a)

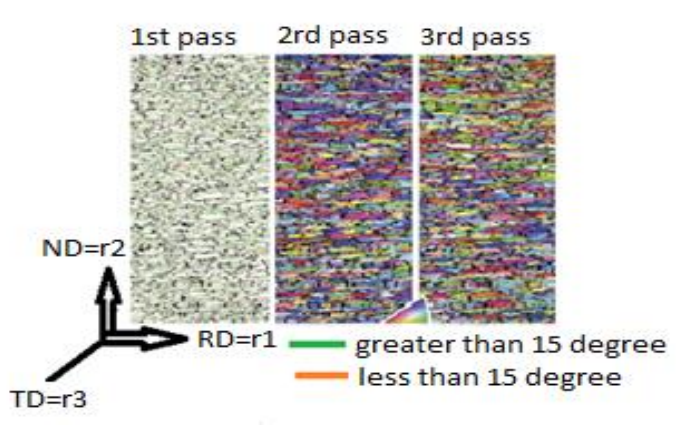

(b)

\section{Figure 1: (a) ARB Process and (b) Grain Elongation on Different ARB Passes after TEM Observation [14]}

From Figure 1 (b), the model of elongation in 2-D and 3-D can be established as defined by Sob et al [14] by relating volume and area as $A=V^{2 / 3}$ given in the model as,

$$
\text { Elongation }=\frac{P r_{0}}{V^{2 / 3} E}
$$


Where the initial length is given as $r_{0}$, the Young modulus of the material during ARB is given as $E$, and the applied force to the system is given as $P$. The material model for Young's modulus $(E)$ of nanomaterials defined by [14] is given as

$$
E=\left(\frac{P}{d}\right)\left(\frac{\left(r^{3}\right)}{192 I}\right)
$$

Where the moment of initial can be inferred during the manufacturing of nanomaterial given as $I=\frac{\pi r_{1}^{4}}{64}, d=d r$ $=\left(r-r_{0}\right), r=$ being defined as the length or equivalent radius of nanocrystallinegrain. It is practically observed during experimentation that the grain-size evolution varies at any instant during ARB and the radii of the nanomaterials during ARB can be related to the equivalent volume of the grain through $(4 / 3) \pi r^{3}=V=(4 / 3) \pi r_{1} r_{2} r_{3}$. This gives

$$
r^{3}=r_{1} r_{2} r_{3}
$$

By putting expression (2) and (3) into expression (1), gives the model of elongation on a 3-D grain during ARB process given as

$$
\text { Elongation }=\frac{3 \pi r_{0} r_{1}^{4}}{r_{2} r_{3} r^{3}}\left(r-r_{0}\right)
$$

The effect of temperature in elongation and other parameters that affect temperature during elongation such as the change in internal energy, and change in energy in the material during elongation can be established as

$$
\begin{aligned}
& d Q=-\left(T_{e x} d s-T_{e x} d P_{S}\right) \\
& d u=-\left(\left(T_{e x} d s-T_{e x} d P_{S}\right)\right. \\
& \Delta E=\delta \frac{4}{3} \pi r^{3}+\phi(t) \sigma\left(\frac{4}{3} \pi r_{0}-\frac{4}{3} \pi r^{3}\right)
\end{aligned}
$$

where $\mathrm{T}_{\mathrm{ex}}$ is the external temperature and $\mathrm{E}$ is the internal energy in the material during elongation by ARB and this impacts the variation of grain sizes variants in the model of elongation defined by equation (4).

Equations (1-8) are solved simultaneously using Engineering Equation Solver software (F-Chart Software, Madison, W153744, USA) and the effect of elongation to failure during ARB passes are revealed

\section{RESULTS AND DISCUSSION}

The derived models developed in this paper was tested with data from (nanocrystalline) aluminum sample (some of which are found in other papers [6\& 14]) are used, which are $M_{0}{ }^{\prime}=0.01 \mathrm{~nm}^{2} \mathrm{~s}^{-1}, m=4, C C=12, a=0.90, D=10^{-4}, h_{0}=0.25 \mathrm{~nm}$, $T_{m}(\infty)=933.47 \mathrm{~K}, C V_{0}=0.3, H_{m}(\infty)=10.71 \mathrm{KJMol}^{l}, \sigma_{0}{ }^{\prime}=16.7 \mathrm{MPa}, K_{t}=1.3, \sigma_{0}=15.40 \mathrm{MPa}, \quad K d=1301.77 \mathrm{MPa}_{-} n m^{1 / 2}, \quad R=8.31 J K^{-}$ ${ }^{1} \mathrm{~mol}^{-1}$ and $T_{r}=300 \mathrm{~K}$. The additional data obtained for this work are $O=0.0035, I=1.1, r_{c l}=1.95 r, r_{0}=100 \mathrm{~nm}, Z=0.4$ Ratio $_{1}=0.81$, Ratio $2=1.071$, and $\tau_{1}=0.000008$. The theoretical simulated results are presented and discussed below. 


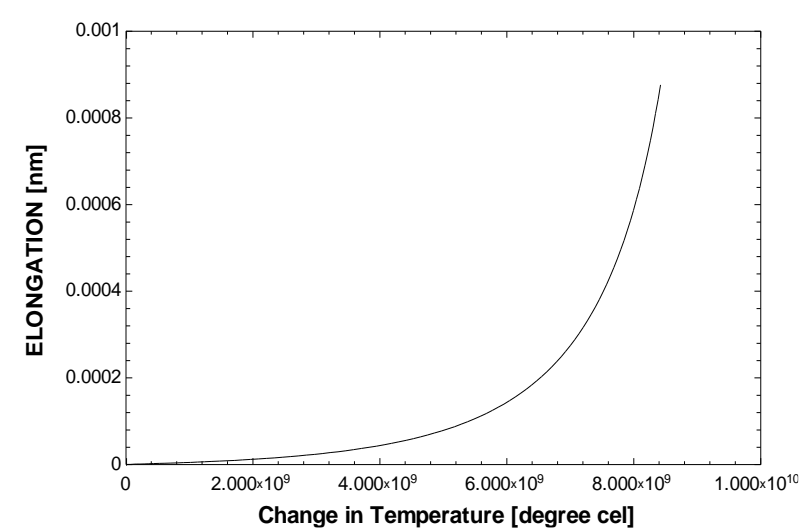

(a)

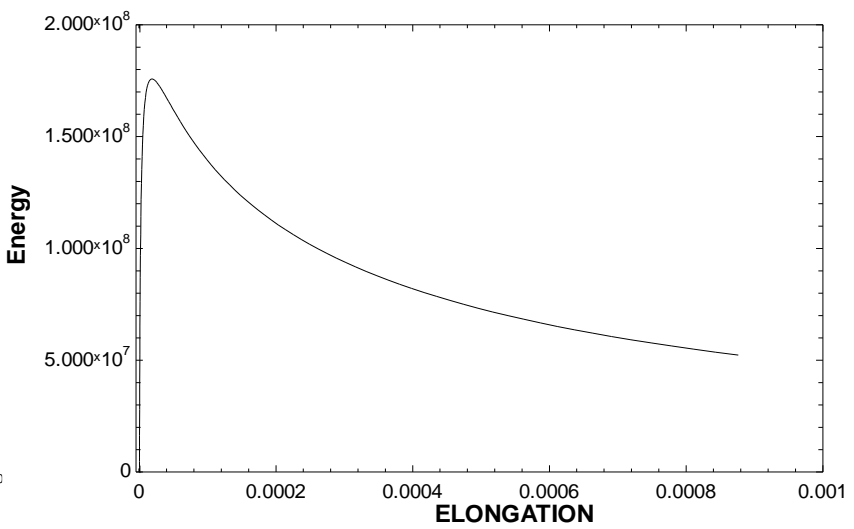

(b)

Figure 2: (a) Elongation and Change in Temperature during ARB, (b), Energy against

\section{Elongation during Grain Refinement}

It should be observed as shown from Figure 2 (a) that the natures of increase of elongation and change in temperature does not increase linearly or exponentially. This is because change in temperature in a material during elongation is affected by several parameters such as dislocation motion, grain rotation coalescence, grain boundaries migration, grain curvature angles and the fraction of high angles grain boundaries that increases during ARB cycle and affect material elongation. This is also because energy and heat are lost due to adiabatic warming and this is affected by change in grain boundaries migration that carries energy along during dislocation motion. The impacts of energy and elongation are shown in Figure 2 (b). Figure 2 (b) revealed that, during the initial process of elongation the material energy rapidly increases which was immediately followed by continuous decrease of energy as elongation increases. This was because the deformed material was being deformed by good internal energy and the internal energy was being transformed as dislocation motion took place during migration of grain particles as the material gets elongation beyond plasticity during ARB. It should be recalled that during the initial process of grain refinement that change in grain boundaries, curvature and dislocation motion led to properties enhancement when the elongation was useful before the plastic rang of the material and as soon as the material gets to its elastic region, elongation to failure begins and the energy in the material is affected as shown in Figure 3

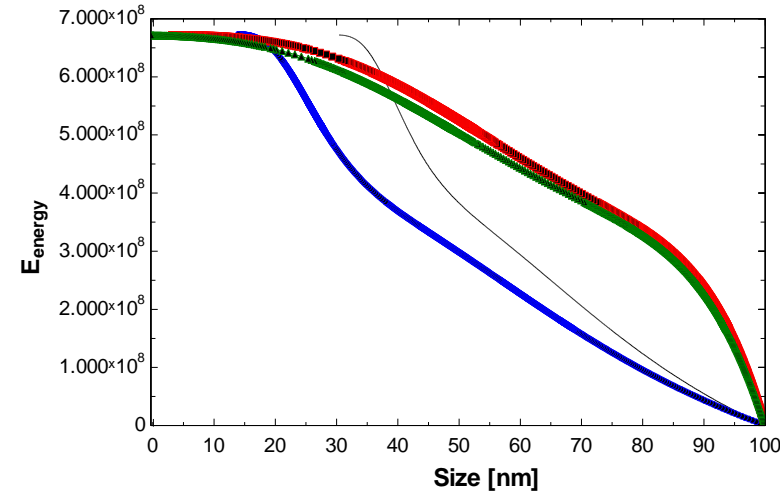

(a)

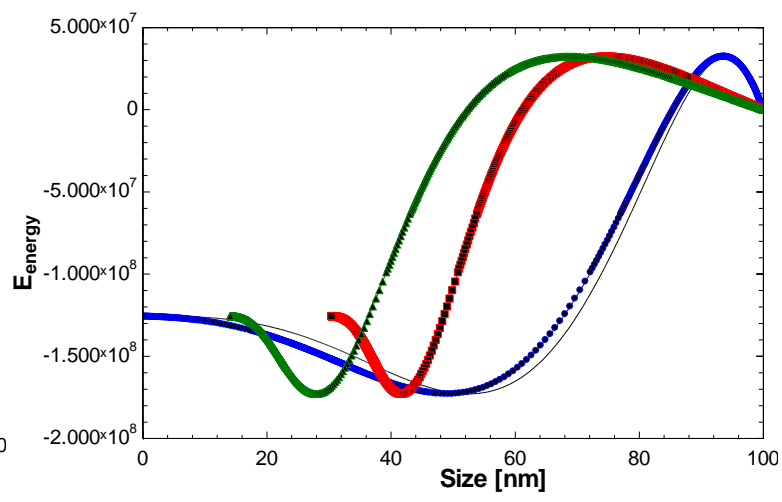

(b)

Figure 3: (a) Energy against Sizes during Useful Elongation by ARB, (b), Energy against Sizes during Elongation to Failure by ARB

The results shown in Figure 3 (a-b) revealed energy and sizes during useful elongation and elongation to failure during ARB process. The results in Figure 3 (a) revealed deformation and useful elongation during ARB process. The material 
energy increases during ARB process as the material sizes decreases from conventional material to nanostructured materials. This was because the change in dislocation motion, grain curvature and the fraction of high angle grain boundaries increase within the elastic limit of the material during ARB. Before the elastic limit of the material, the elongation is useful, and the material developed the desired property enhancement with the acceptable energy during ARB. As the deformed material exceeds it elastic region, the grain boundaries angles became lower and elongation to failure begins as the material energy start falling as shown in Figure 3 (b). Therefore, Figure 3 (b) revealed a decrease in sizes led to decrease in energy since elongation to failure was being observed during ARB process. Therefore, the optimal energy the material can withstand before elongation to failure during ARB process has been revealed.

\section{CONCLUSIONS}

The aim of the current paper was to investigate the effect of temperature on elongation after several ARB. To achieve that, the model of elongation on temperature during ARB process was developed in order to find the optimal temperature to achieve maximum elongation. The tool of stochastic mechanics was used to model the random change in grain size and temperature during elongation. It was shown that, during the initial process of grain elongation, the material energy increases, and this was immediately followed by a decrease in energy as elongation increases. This was due to the due change in grain boundaries migration and grain curvature during ARB. It was also shown that, the material energy increases as the material sizes decreases from conventional material to nanostructured materials. This change affected temperature and elongation during ARB process. It was revealed that the change in dislocation motion, grain curvature and the fraction of high angle grain boundaries increase within the elastic limit of the material during ARB which was followed by plasticity at the optimal elongation when elongation to failure was revealed during ARB.

\section{REFERENCES}

1. Borhani, E., Jafarian, H., Shibata, A., Tsuji, N., Mater. Trans., Vol. 53 (2012) pp.1863-1869.

2. Jafarian, H., Borhani, E., Shibata, A., Terada, D., Tsuji, N., Mater. Sci. Forum, Vol. 667 (2010) pp.361-366.

3. Borhani, E., Jafarian, H., Adachi, H., Terada, D., Tsuji, N., Mater. Sci. Forum, Vol. 667 (2010) pp.211-216.

4. Tsuji, N., Encyclopedia of Mate. Sci. \& Tech., (2011) pp.1-8.

5. Borhani, E., Ph.D. thesis, Kyoto University of Japan, 115p. (2012). [6].Sato, T., Terada, D., Tsuji, N., Mater. Sci. Forum, Vol. 584-586 (2008) pp. 728-733

6. Lee, S., Berbon, P. B., Furukawa, M., Horita, Z., Nemoto, M., Tsenev, N. K., Valiev, R. Z., Langdon, T. G.; Mater. Sci. \& Eng., Vol. A272 (1999) pp.63-72.

7. Smolej, A., Skaza, B., Dragojevic, V., JMEPEG Vol. 19 (2010) pp.221-230.

8. Kawasaki, M., Balasubramanian, N., Langdon, T. G., Mate. Sci. \& Eng., Vol. A528 (2011) pp.6624-6629.

9. Lee, S., Utsunomiya, A., Akamatsu, H., Neishi, K., Furukawa, M., Horita, Z., Langdon, T.G.; Acta Mater., Vol. 50 (2002) pp.553-564.

10. Lee, S., Furukawa, M., Horita, Z., Langdon, T. G.; Mater. Sci. \& Eng., Vol. A342 (2003) pp.294-301.

11. Borhani, E., Jafarian, H. R., Terada, D., Adachi, H., Tsuji, N., Mater. Trans., Vol. 53 (2012) pp.72-80 
12. $P B$ Sob, AA.Alugongo and TB Thomas (2020) Controllability and stability of selectively wettable nanostructured membrane for oil-water separation. A thesis submitted in fulfillment of the requirements for the degree Doctorate Technologiae in Mechanical Engineering, In the Faculty of Engineering \& Technology

13. PB Sob, AA.Alugongo and TB Thomas MODELLING STRAIN RATE SENSITIVE NANOMATERIALS' MECHANICAL PROPERTIES: THE EFFECTS OF VARYING DEFINITIONS. A dissertation submitted in fulfillment of the requirements for the degree Magister Technologiae in Mechanical Engineering, In the Faculty of Engineering \& Technology.

14. P.B. Sob (2020). Improving the mechanical efficiency of a Pelton Wheel impulse turbine at Low head during operation. IJERT. ISSN 0974-3154, Volume 13, Number 7 (2020), pp. 1508-1515

15. P.B. Sob (2020). Modeling and simulation of kinetic energy and it impact on the conservation of energy in an automotive hydraulic shock absorber during damping process. IJERT. ISSN 0974-3154, Volume 13, Number 7 (2020), pp. 1575-1583

16. P.B. Sob, T.B. Tengen and A.A. Alugongo (2020). A Conceptual Model Based on Nanoscience and Nanotechnology in Design of Smart Home for Energy Efficiency. IJERT. ISSN 0974-3154, Volume 13, Number 1 (2020), pp. 100-106.

17. P.B. Sob, T.B. Tengen and A.A. Alugongo (2020). The Stochastic Effect of Nanoparticles Inter-Separation Distance on Membrane Wettability During Oil/Water Separation. IJERT. ISSN 0974-3154, Volume 13, Number 5 (2020), pp. 742-766.

18. P.B. Sob (2020). Performance improvement of a centrifugal pump filtration system for industrial and domestic applications. IJERT. ISSN 0974-3154, Volume 13, Number 5 (2020), pp. 942-966

19. P.B. Sob (2020). Strain rate effect of size variants and tensile behaviour of 608276 aluminium during deformation by accumulative roll bonding. IJERT. ISSN 0974-3154, Volume 13, Number 5 (2020), pp. 542-566

20. P.B. Sob (2020). Enhancing nanocrystalline material yield strength during ARB process by using Solute atoms as reinforcement. IJERT. ISSN 0974-3154, Volume 13, Number 9 (2020), pp. 2519-2525

21. P.B. Sob (2020). The effects of the different approaches of measuring size of nanocrystalline materials on their thermodynamic properties. IJERT. ISSN 0974-3154, Volume 13, Number 9 (2020), pp. 2505-2510.

22. P.B. Sob (2020). Modelling the Design of a Centrifugal Pump Shaft that can Withstand Fatigue Failure Rate, Stress and Strain during Backpressure. IJERT. ISSN 0974-3154, Volume 13, Number 10 (2020), pp. 3017-3024.

23. P.B. Sob (2020). Modelling and Simulating Stress Distribution on a Centrifugal Pump Shaft during Backpressure IJERT. ISSN 0974-3154, Volume 13, Number 10 (2020), pp. 3037-3048

24. P.B. Sob (2020). Modelling the Impacts of Liquid Entry Pressure on Membrane Performance during Oil-Water Separation. International Journal of Engineering Research and Technology. ISSN 0974-3154, Volume 13, Number 12 (2020), pp. 41634170 @ International Research Publication House. http://www.irphouse.com

25. P.B. Sob (2020). Modelling the Effect of Pressure Waves and Velocity of Flow on Membrane Performance During Oil-Water Separation. International Journal of Engineering Research and Technology. ISSN 0974-3154, Volume 13, Number 12 (2020), pp. 4191-4198 @ International Research Publication House. http://www.irphouse.com

26. [27] P.B. Sob (2020). Modelling the Separability Process of Oil-Water Molecular Motion for Stable and Efficient Wettability Process. International Journal of Engineering Research and Technology. ISSN 0974-3154, Volume 13, Number 12 (2020), pp. 4211-4217 @ International Research Publication House. http://www.irphouse.com

27. P.B. Sob, A. Alungogo and T.B. Tengen, (2019), Scanning electron microscopy, energy dispersive X-ray Spectroscopy and statistical analysis of high-and low-pressure coating on sediment membrane for efficient wettability process during oil/water 
separation. International Journal of Engineering Research and Technology (IJERT). ISSN 09743154, Volume 12, Number 12 (2019), pp. 2698-2717.

28. P.B. Sob, A. Alungogo and T.B. Tengen, (2017), Stochastic Effect of Grain-Elongation on Nanocrystalline Materials Strain and Strain Rate Produced by Accumulative Roll-Bonding and Equal Channel Angular Pressing", Advances in Materials Science and Engineering, vol. 2017, Article ID 5418769, 9 pages, 2017. doi:10.1155/2017/5418769. ISSN: 1687-8434, EISSN: $1687-8442$

29. P.B. Sob, A. Alungogo and T.B. Tengen, (2017), Cracks Propagation as a Function of Grain Size Variants on Nanocrystalline Materials Yield Stress Produced by Accumulative Roll-Bonding, Advances in Materials Physics and Chemistry (AMPC) Vol. 7 , No. 2, pp. 58-69. doi: 10.4236/ampc.2017.72006., ISSN: 2162-531X (Print), ISSN: 2162-5328 (Online)

30. P.B. Sob, A. Alungogo and T.B. Tengen, (2015), Determination of Strain Rate Sensitivity (SRS) for Grain Size variants on Nanomaterials Produced by ARB and ECAP, (International Science Index), International journal of Chemical, Molecular, Nuclear, Materials and Metallurgical Engineering, Vol:9, No:12, 2015, pp 1276-1280, eISSN 1307-6982

31. P.B. Sob, A. Alungogo and T.B. Tengen, (2015), The Effect of Deformation Activation Volume, Strain Rate Sensitivity and Processing Temperature on Grain Size Variant, (International Science Index), International Journal of Mechanical, Aerospace, Industrial, Mechatronics and Manufacturing Engineering Vol:9, No:11, 2015, pp 1789-1792, eISSN 1307-6982

32. P.B. Sob and M. Pita (2020). Experimental Study on the performance of a vertical packing cooling tower at various flow rates. 2020 IEEE 11th International Conference on Mechanical and Intelligent Manufacturing Technologies. ISBN: 978-1-7281$5331-5$.

33. P.B. Sob and M. Pita (2020). Simulation and theoretical analysis of the impact of velocity, pressure and kinetic energy during damping in a shock absorber. 2020 IEEE 11th International Conference on Mechanical and Intelligent Manufacturing Technologies. ISBN: 978-1-7281-5331-5.

34. P.B. Sob and M. Pita (2020). Stochastic effect of fracture toughness and toughening mechanism on nanocrystalline material size variants produced by accumulative roll bonding. 2020 IEEE 11th International Conference on Mechanical and Intelligent Manufacturing Technologies. ISBN: 978-1-7281-5331-5.

35. P.B. Sob, T.J. Muhanelwa, A. Alungogo and T.B. Tengen, (2020). The design of spray nozzle for washing aggregates in the mining industry. 2nd African International Conference on Industrial Engineering and Operations Management, online Harare, Zimbabwe, December 8-10, 2020. ISSN: 2169-8767 (U.S. Library of Congress)

36. P.B. Sob (2020). OPTIMISING THE VELOCITY AND DISCHARGE PRODUCED BY A SPRAY NOZZLE FOR EFFICIENT WASHING OF AGGREGATES IN A MINING INDUSTRY. 2nd African International Conference on Industrial Engineering and Operations Management, online Harare, Zimbabwe, December 8-10, 2020. ISSN: 2169-8767 (U.S. Library of Congress).

37. P.B. Sob and M. Pita (2020). Designing and Simulation a Centrifugal Pump Shaft with Enhanced Mechanical Properties During Backpressure. 2nd African International Conference on Industrial Engineering and Operations Management, online Harare, Zimbabwe, December 8-10, 2020. ISSN: 2169-8767 (U.S. Library of Congress)

38. P.B. Sob and M Pita (2020). Simulating and Optimizing the Stress Distribution on a Centrifugal Pump Shaft due to Varying Backpressure Intensity. 2nd African International Conference on Industrial Engineering and Operations Management, online Harare, Zimbabwe, December 8-10, 2020. ISSN: 2169-8767 (U.S. Library of Congress)

39. P.B. Sob and M. Pita (2019). Design of Solar Powered Grass Trimmer. In the proceedings of SAIIEneXXXt, 30th September 2nd October 2019, Port Elizabeth, South Africa 2019. 
40. [P.B. Sob, A. Alungogo and T.B. Tengen, (2018), The stochastic effects of nano-particles size, morphology and spatial distribution on surface energy (SACAM 2018). Proceedings of the 11th South African Conference on Computational and Applied Mechanics, held on the 17 - 19 September 2018 at the Faculty of Engineering and Technology Vaal University of Technology Vanderbijlpark, South Africa, pages 1-10, ISBN: 978-1-77012-143-0 and 978-1-77017-144-7.

41. P.B. Sob, A. Alungogo and T.B. Tengen, (2018), The stochastic effect of nano-particles size, morphology, spatial distribution on flow rate through a nanostructured membrane surface (SACAM 2018). Proceedings of the 11th South African Conference on Computational and Applied Mechanics, held on the 17 - 19 September 2018 at the Faculty of Engineering and Technology Vaal University of Technology Vanderbijlpark, South Africa, pages 1-9, ISBN: ISBN: 978-1-77012-143-0 and 978-1-77017144-7.

42. P.B. Sob, A. Alungogo and T.B. Tengen, (2018), Relationship between surface tension and surface energy in oil/water separation process (SACAM 2018). Proceedings of the 11th South African Conference on Computational and Applied Mechanics, held on the 17 - 19 September 2018 at the Faculty of Engineering and Technology Vaal University of Technology Vanderbijlpark, South Africa, pages 1-11, ISBN: 978-1-77012-143-0 and 978-1-77017-144-7.

43. P.B. Sob, A. Alungogo and T.B. Tengen, (2018), Relating the parameters of flow rate, surface tension and surface energy to nanoparticles (SACAM 2018). In Proceedings of the 11th South African Conference on Computational and Applied Mechanics, held on the 17 - 19 September 2018 at the Faculty of Engineering and Technology Vaal University of Technology Vanderbijlpark, South Africa, pages 1-10, ISBN: 978-1-77012-143-0 and 978-1-77017-144-7.

44. P.B. Sob, A. Alungogo and T.B. Tengen, (2018), The effect of random dynamic forces on membrane surfaces and their impact on surface energy, surface tension and flow rate during oil/water separation. Proceedings of the 11th South African Conference on Computational and Applied Mechanics, held on the 17 - 19 September 2018 at the Faculty of Engineering and Technology Vaal University of Technology Vanderbijlpark, South Africa, pages 1-10, ISBN: 978-1-77012-143-0 and 978-177017-144-7.

45. P.B. Sob, TB Tengen, and A. Alugongo (2016) Stochastic Model of Energy on Nanocrystalline Materials Produced by Accumulative Roll-Bonding, in Proceedings of the 10th South African Conference on Computational and Applied Mechanics, held on the 3 - 5 October 2016 at the Faculty of Engineering, North-West University, Potchefstroom, South Africa,ISBN: 978$1-86822-673-3$.

46. 20. P.B. Sob, T.B. Tengen, and A. Alugongo (2016), The effects of the size variants of nanocrystalline materials on their energy, thermodynamics and mechanical properties produced by Accumulative Roll-Bonding, in Proceedings of the 10th South African Conference on Computational and Applied Mechanics, held on the 3 - 5 October 2016 at the Faculty of Engineering, North-West University, Potchefstroom, South Africa, ISBN: 978-1-86822-673-3.

47. P.B. Sob, A. Alugongo and T.B. Tengen, (2016), The Effects of Grain Size Variants on Fracture Toughness of Nanocrystalline Materials Produced by Accumulative Roll Bonding, , in Proceedings of the 10th South African Conference on Computational and Applied Mechanics, held on the 3 - 5 October 2016 at the Faculty of Engineering, North-West University, Potchefstroom, South Africa, ISBN: 978-1-86822-673-3.

48. P.B. Sob, A. Alungogo and T.B. Tengen, (2015), Determination of Strain Rate Sensitivity (SRS) for Grain Size variants on Nanomaterials Produced by ARB and ECAP, (International Science Index), International journal of Chemical, Molecular, Nuclear, Materials and Metallurgical Engineering, Vol:9, No:12, 2015, pp 1276-1280, eISSN 1307-6982.

49. P.B. Sob, A. Alungogo and T.B. Tengen, (2015), The Effect of Deformation Activation Volume, Strain Rate Sensitivity and Processing Temperature on Grain Size Variant, (International Science Index), International Journal of Mechanical, Aerospace, Industrial, Mechatronics and Manufacturing Engineering Vol:9, No:11, 2015, pp 1789-1792, eISSN $1307-6982$. 
50. P.B. Sob, A. Alungogo and T.B. Tengen, (2014), Stochastic Effect Of Grain Elongation On Nanocrystalline Material Yield Stress Produced By Accumulative Roll Bonding, In Proceeding of the 9th South African conference on Computational and Applied Mechanics, 14-16 January 2014, pp [SACAM14_074]-1-9, ISBN: 978-0-620-58994-6.

51. Karthika Krishnan \& V. Thangamani, "Quantitative Apprisal of Areal Parameters in Morphometric Study of Malattar River Basin” BEST: International Journal of Humanities, Arts, Medicine and Sciences (BEST: IJHAMS), Vol. 4, Issue 1, pp. 137142

52. Chennakesava Reddy, "Low and High Temperature Micromechanical Behavior of BN/3003 Aluminum Alloy Nanocomposites “, International Journal of Mechanical Engineering (IJME), Vol. 6, Issue 4,pp. 27-34

53. V. Yashodhakumari, H. M. Devaraja \& S. Sugumar, "Comparative Study of Mechanical Properties of Different 3 Plain Weave Cotton Fabrics "International Journal of Industrial Engineering \& Technology (IJIET), Vol. 8, Issue 1, pp. 1-8

54. Mohammad S. Alsoufi \& Mohammed Yunus, "Effect of Heat Treatment on Stress Corrosion Cracking Resistance of Al-ZnMg-Cu Alloy Used in Aerospace Engineering Applications “, BEST: International Journal of Management, Information Technology and Engineering (BEST: IJMITE), Vol. 3, Issue 8, pp. 19-34 
